\title{
Reflexiones en torno a la historia de las emociones, la historia del tiempo presente y la experiencia
}

\author{
Daniela Belmar Mac-Vicar ${ }^{1}$ \\ Recibido: 15 de febrero de 2019 - Aprobado: 22 de abril de 2019
}

\begin{abstract}
Resumen
Este trabajo reflexiona acerca de los antecedentes antropológicos, sociológicos y psicológicos que durante los últimos veinte años los historiadores le han atribuido a la historia de las emociones. Los hallazgos de estas disciplinas en ese campo, les ha permitido a los historiadores argumentar que las emociones 0, al menos, la expresión de ellas, varía culturalmente. Desde estas referencias, los historiadores han podido justificar el estudio historiográfico de las emociones, ya que ellas tendrían historicidad. Pese a lo anterior, se plantea que esa relación con las ciencias sociales obstaculiza cuestionamientos más profundos respecto de la historicidad de las emociones y, específicamente, respecto de su tratamiento historiográfico. En la misma línea, se propone que dicha vinculación con las Ciencias Sociales dificulta la evaluación de los efectos que las emociones provocaron en el pasado, $y$, al mismo tiempo, en el presente. Dicho esto, se revisan sus antecedentes a la luz de la historia del tiempo presente y la historia de la experiencia.
\end{abstract}

Palabras clave: historia de las emociones, ciencias sociales, historia del tiempo presente, experiencia

\section{Reflections on the History of Emotions, History of the Present Time and the History of Experience \\ Abstract}

This article reflects on the anthropological, sociological and psychological background attributed by historians during the last twenty years to the history of emotions. The fieldwork findings of these disciplines have allowed historians to argue that emotions, or at least their expression, varies culturally. Using these as a reference, historians have been able to justify the historiographic study of emotions. Nevertheless, it is proposed that this relation to the social sciences impedes a more in-depth inquiry into the history of emotions and, 
specifically, its historiographic treatment. In the same line, it is proposed that these ties to the social sciences makes it difficult to evaluate the effects caused by emotions in both the past and present. That said, the background of emotions is reviewed in light of modern history and the history of experience.

Keywords: history of emotions, social sciences, modern history, experience

Hacia los años 2000, la pregunta sobre las emociones, los sentimientos, los afectos o las pasiones, comenzó a ser articulada como una corriente de investigación por la historiografía. Su carácter escurridizo y poco definido, sin embargo, persiste y dificulta su tratamiento historiográfico. De hecho, durante el siglo XX, los intentos por abordarlas directamente, salvo en casos excepcionales y de corto aliento (como la psicohistoria), fueron ampliamente criticados y, en 2005, Peter Burke señaló que el tratamiento de las emociones carecía de un marco analítico que posibilitara su estudio, ya que ni siquiera había consenso respecto a su significación y denominación (emoción, sentimiento, afecto o pasión, por ejemplo). Pese a ello, la producción historiográfica al respecto ha sido inmensa.

Aun cuando la historia de las emociones actualmente tiene un campo validado dentro de la disciplina, las reticencias que ha provocado siguen vigentes y se deben, en primer lugar, a las consideraciones que podemos hacer respecto de su naturaleza. Este asunto ha sido ya ampliamente referido por la literatura historiográfica existente: ¿las emociones son esenciales, biológicas e inmutables a lo largo del tiempo, o, por el contrario, responden a los contextos sociales con las implicaciones que la cultura y el tiempo ejercen sobre ellos? (Zaragoza, 2013). Esta pregunta, que a priori podría parecernos superficial por su extremismo y polarización, tiene implicancias teóricas y metodológicas que, a mi juicio, son relevantes no solo para los efectos de la historia de las emociones sino, mucho más profundamente, respecto de nuestra comprensión (y escritura) de la historia en general. De todos modos, la condición que les presupongamos impacta directamente en su posibilidad de historización.

Para autores como Juan Manuel Zaragoza (2013) o William Reddy (2001), esta discusión es una herencia de otras disciplinas, como la antropología, la sociología o la psicología, las cuales comenzaron a abordar académicamente las emociones hacia la mitad del siglo XX (Giazú y Lara, 2014). A pesar de las muchas referencias que pueden hallarse en la literatura historiográfica de los siglos precedentes sobre las emociones², los

Pese a esto, la literatura rescata las contribuciones de Lucien Febvre (1941), quien reclamó explícitamente un lugar para las emociones en la historiografía. Además, se destacan los 
historiadores suelen referir su origen a autores provenientes de la sociología de la primera mitad del siglo como Nobert Elias (1993) y, así, a relacionarlas con disciplinas de las ciencias sociales (Moscoso, 2015). De hecho, en el año 2001, Reddy elaboró una ambiciosa propuesta teórica que tiene como objetivo historiografiar las emociones. En ella ofrece un marco analítico fundado en los conocimientos que han proporcionado materias tales como la psicología y la antropología.

Para historiadores como Peter y Carol Stearns (1985), William Reddy (2001) o Barbara Rosenwein (2002), entre otros, entender las emociones desde la perspectiva del constructivismo cultural (en contraposición a otras de orden biológico) no solo ha sido una elección sino también la única posibilidad a través de la cual permitir su estudio. Esto no quiere decir que desconsideren sus (presumibles) fundamentos biológicos (y de los cuales debieran hacerse cargo otras disciplinas como la neurociencia, la psicología o la psiquiatría, entre otras), sino que reconocen que hay aspectos de su socialización que se modifican con el paso del tiempo y con los cambios culturales, sociales y políticos (Zaragoza, 2013). Este entendimiento de las emociones permite sugerir que dichas variaciones, relacionadas a la cultura, no solo alterarían sus expresiones sociales sino también las maneras en que las personas las experimentan y significan en términos subjetivos.

Una discusión polarizada al respecto parece ser, a juicio de los autores citados, "consecuencia directa de la falta de problematización" (Zaragoza, 2013: 2) y respondería a la vieja contraposición entre naturaleza y cultura. Otros, como Jan Plamper (2015), son aún más severos: esta discusión no tiene sentido ${ }^{3}$, entre otras cosas porque involucra conocimientos respecto de las emociones que se desconocen y en los que la historiografía no posee jurisdicción. Según Plamper, este conflicto remite, además, a dogmas ilustrados que las ciencias sociales (y la historia) reactualizaron en la primera mitad del siglo XX con una intención de contribuir a las políticas públicas. A mi juicio, este debate, antes que ayudar, entorpece y retrasa el desarroIlo de otras discusiones directamente atingentes al trabajo historiográfico sobre emociones.

aportes de algunos autores como Johan Huizinga, Philippe Aries o Jacques Le Goff, entre otros, pero en general no protagonizan los antecedentes de esta corriente historiográfica. Plamper (2015:8) señala "These borrowings often look like a binge that will be closely flowed by the most dreadful hangover $-\mathrm{I}$ am quite certain of that". [Traducción propia: "Estos préstamos a menudo se ven como un atracón que será cercamente seguido de la resaca más terrible. Estoy bastante seguro de eso"]. 


\section{Ciencias sociales y emociones}

Es evidente que el desarrollo científico social ha ofrecido a las humanidades pisos conceptuales mínimos a través de los cuales justificar y fundar sus estudios sobre las emociones. En la antropología, la sociología y lo que en los últimos años ha sido denominado como "saberes psi", encontramos ejemplos de ello. Charles Darwin es el primer antropólogo que trabaja cierto contenido emocional en sus investigaciones, en su obra La expresión de las emociones en el hombre y en los animales, publicada en inglés por primera vez en 1873. Acorde con las convicciones ilustradas, Darwin plantea que, aparentemente, las personas de diferentes culturas experimentan las mismas emociones y que así ellas responden ante lo social a algo que les es inherente. Poco más de un siglo después, en 1971, Paul Ekman presentó un artículo en el que a través de una serie de fotografías analizaba cómo las emociones eran vivenciadas de manera similar por las personas en distintos lugares del mundo. Con más de un siglo de distancia, ambos autores entendieron las emociones (y su expresión) como un fenómeno universal. A pesar de la similitud de sus conclusiones, presumiblemente sus objetivos y su trasfondo teórico (incluso político) es diferente. ${ }^{4}$ De todos modos, pese a que estas y otras investigaciones del periodo comprenden las emociones como un fenómeno universal, "el catálogo de emociones universales no es nunca el mismo para los diferentes autores" (Surrallés, 1998: 293).

A partir de la década de 1970, sin embargo, la antropología ya había comenzado a plantear hipótesis culturalistas en sus investigaciones. Es el caso, por ejemplo, de la acuñación del concepto "descripción densa", en 1973, por parte de Clifford Geertz (1983), el que plantea que una descripción etnográfica debiera ser capaz de interpretar las significaciones sociales. Geertz resalta el papel del antropólogo como quien interpreta lo que ya ha sido interpretado. Este tipo de tesis impactaron en los estudios antropológicos sobre las emociones y en 1998 David Le Bretón publicó el libro Las pasiones ordinarias (1998/2009), en el que concluye que existen diferencias en los modos en que las distintas culturas significan las emociones. Sin desconsiderar las posibles condiciones biológicas al respecto, puso en el centro de las experiencias subjetivas y las emociones a la cultura primero, y luego a la

\footnotetext{
Considerando los contextos en los que escribe cada cual, es posible pensar que el efecto de este planteamiento naturalista opere de manera distinta en cada uno de estos autores. Darwin, por un lado, vive en una época en la que la esclavitud (y específicamente la discusión sobre el si todos los seres humanos tenían alma), por ejemplo, seguía articulándose en algunos lugares del mundo, por lo tanto, las consecuencias políticas de plantear que todos los seres humanos tenían las mismas emociones podrían ser distintas a las del planteamiento de Ekman, que vive en una época en la que el concepto de naturaleza sería síntoma del más alto conservadurismo.
} 
capacidad de agencia de los sujetos: "El individuo no es su cultura, sino lo que hace de ella. Cada uno impone su toque personal al rol que juega, ya sea con sinceridad o con distancia, pero un esbozo se mantiene y hace las actitudes reconocibles" (Le Bretón, 2013: 73).

Pese a sus pretensiones universalistas, ya en sus orígenes, en el siglo XIX, los sociólogos esbozaron interpretaciones que pusieron en el centro de sus investigaciones a la cultura. De hecho, algunos autores que son referentes en esa disciplina, tales como Émile Durkheim o Max Weber, aunque de manera residual, trataron el ámbito de los afectos en sus investigaciones (Bericat, 2000). La posibilidad de pensar las reacciones afectivas como efectos de la cultura ya se puede observar en la obra El suicidio, de Durkheim, en la que establece un tipo particular de muerte voluntaria: el suicidio anómico. En ese caso, el suicidio es concebido como una consecuencia afectiva del aislamiento (en términos socioafectivos) que la modernidad produce en algunos individuos. Con esta tesis, Durkheim instala dichas conductas en el plano de lo histórico, aun cuando su objetivo sea más bien socioestadístico que afectivo. En el siglo XX, y de manera mucho más delibrada, Norbert Elias refiere a los afectos y al comportamiento social y publica en 1939 el libro El proceso de la civilización: investigaciones sociogenéticas y psicogenéticas. En este trabajo, el autor desarrolla una interpretación de las relaciones sociales en la sociedad europea, especialmente en Alemania, Inglaterra y Francia. En su análisis, el tratamiento de cierta normatividad social (y de las emociones asociadas a ella) aparecen como una consecuencia de la educación, la cultura y, en esta línea, de las concepciones de civilización propias de la modernidad (Montesinos y Martínez, 2001). En este sentido, la teoría sociológica de Elias es una teoría cultural de la modernidad que intenta explicar y estructurar las vinculaciones sociales que permiten una constitución social particular.

En las últimas décadas, una rama de la historia de las ciencias, denominada saberes "psi", ha contribuido a la discusión historiográfica sobre las emociones, al indagar respecto de cómo la medicina ha entendido los comportamientos sociales que, en el pasado, escaparon al sentido común y que usualmente son descritos (y explicados) a través de las expresiones emocionales de los sujetos. Es el caso, por ejemplo, de Germán Berrios, médico psiquiatra que en 1996 publicó el libro Historia de los síntomas y trastornos mentales. La psicopatología descriptiva desde el siglo XIX (1996/2013), desde una perspectiva -y desde una pretensión- claramente científico-médica. En este trabajo el autor describe los síntomas de los trastornos de la mente según la medicina del pasado, como la neurastenia y la melancolía, entre otras. Otro exponente de esta corriente es el historiador Rafael Huertas que, en 2012, publicó Historia cultural de la psiquiatría, en el que historiza las enfermedades mentales descritas por la psiquiatría de las últimas dos décadas anteriores a su publicación. Es destacable que el autor señale que la medicina mental 
aun no consigue definir científicamente categorías claras respecto a cuánto de la genética y cuánto de la biología opera en los diagnósticos psiquiátricos.

Algunos de los principales representantes de la historia de las emociones han considerado que hay claves en las investigaciones mencionadas que permiten justificar los estudios historiográficos ( $y$, más particularmente, la historicidad de los sentimientos). Las conclusiones de sus autores comprueban que la cultura sí juega un papel relevante en la manera en que las personas se relacionan con otros, en las maneras en que expresan sus emociones y en el modo en que las significan a través del lenguaje. Sin embargo, ahondar en esta discusión implica preguntarse otras cuestiones que, por el momento, no tienen respuestas definitivas y que profundizan las interrogantes de la historiografía. Entre ellas, las que me parecen más relevantes son respecto a la proporcionalidad en que influyen la cultura y la biología en los individuos; la dependencia entre ellas; cómo ocurren los cambios culturales que afectan los comportamientos, las emociones y las formas de sentir; $y$, finalmente, a mi entender la que tiene más implicancias éticas, está relacionada con cómo se vinculan las nociones culturalistas y científicas con los conceptos "autonomía" y "libertad", y sobre cómo se les entiende. Aunque varios autores, sobre todo provenientes desde la filosofía, han esbozados aproximaciones a algunos de estos temas, aún no existe una teoría científica unificada o, al menos, parcialmente desarrollada que pueda responder a estas interrogantes.

\section{Las emociones como historiografía}

Considerando lo anterior, me interesa sugerir que la manera en que decidamos abordar históricamente las emociones no solo impactará en esta corriente específica, si no mucho más profundamente en los fundamentos de la historiografía. Dicho de otra forma, las emociones nos interrogan respecto a la comprensión misma que hacemos respecto a los asuntos históricos (Arendt, 1995). Las emociones han sido tradicionalmente entendidas, tanto por las disciplinas asociadas a la salud mental como por las humanidades, como algo que usualmente excede el razonamiento lógico. Tanto en sentido positivo como negativo, las situaciones límites evidencian este exceso de manera evidente: desde aquellos actos que se consideran heroicos hasta los crímenes pasionales. La cultura popular es rica en refranes que relacionan la emocionalidad con expresiones humanas que colindan con la sinrazón e, incluso, con la locura: "tiene el corazón razones, que nadie sabe explicar". ${ }^{5}$

Referencia a canción titulada "Sin ti no puedo vivir" de la cantante peruana María Dolores Pradera. 
Las expresiones de amor, ira, asombro o alegría, por ejemplo, con frecuencia escapan a las normas sociales establecidas por la cultura y el sentido común, o, al menos, las difuminan. Si bien, en términos generales, todas las disciplinas destacan el valor social de las emociones ya que permiten la construcción de lazos sociales que otorgan sentido profundo a la existencia humana, también han sido consideradas como peligrosas cuando su carácter excesivo pone en riesgo la vida, la paz o, también, la posibilidad de trabajar o llevar una vida sustentable en términos económicos. Incluso su riesgo queda en evidencia en aquellos momentos en que el comportamiento de algunas personas devela sentimientos excesivos que no nos permiten tener criterios previsibles respecto de sus acciones y decisiones. A partir de lo anterior, se entiende que a lo largo de la modernidad, una época de la historia en la que tanto los intelectuales como los gobernantes buscaron frenéticamente el orden a través de la racionalidad científica en pos de la noción de progreso, e incluso hasta nuestros días, se intentara e intente objetivar el campo emocional en favor de su control y previsibilidad (Delgauff, 1968).

Las críticas de Zaragoza y Plamper (2015) respecto de una discusión demasiado taxativa en torno a la naturaleza de las emociones no responden tanto a que contravengan la necesidad de hacerla como a la insistencia entorno a ella. Sobre todo, porque consideran que es una especie de problema irresoluble que debiera ser superado para poder discutir otras cuestiones más específicas y atingentes históricamente. Específicamente, respecto de las formas en que las expresiones emocionales varían y en cómo las sociedades les han asignado significados sociales. ${ }^{6}$ Yendo un poco más lejos, estimo que una preocupación implícita detrás de este tipo de críticas recae en el interés por analizar los grados de agencia o de autonomía con los cuales las personas posicionan, o atribuyen, sus acciones ante los otros (Wittgenstein, 2009) y en cómo ellas varían a lo largo de tiempo. En este sentido, aun cuando no ha sido profundizada, a mi juicio, la crítica a esta discusión preliminar, considero que en ella reposan consideraciones éticas que subyacen a la noción más antigua de la historiografía: un entendimiento según el cual cada aconte-

6 De hecho, Plamper recuerda la rapidez con la que los científicos generan teorías que luego niegan a causa de nuevos hallazgos: "Son los historiadores los que se ven en problemas si deciden fundar su investigación en ciencias de la vida con verdades "eternas" y "universales" que luego resultan ser equivocadas" (2014: 29) y por ello, hace un llamado a los historiadores a que estén al tanto de las investigaciones biológicas. En esta línea, el autor plantea que los desafíos que plantea la historia de las emociones son varios: la realización de una historia conceptual "meta multilingüe de emociones, afectos, pasiones, sentimientos, estados de ánimo, etc." (2014: 27); un desarrollo aún mayor de la historia de las ciencias en vinculación a las emociones; el análisis sobre cómo opera la relación entre emociones y medios de comunicación; el estudio respecto del impacto que generan las emociones en la economía y en el trabajo; y, por último, las posibilidades de estudio emocional a través de la historia oral. 
cimiento es singular. Esto quiere decir que, para la historiografía, los actos, de una manera u otra, ya sea que estén determinados por la cultura o la biología (en el peor de los casos), o, por el contrario, estén abiertos a la libre experiencia histórica de los sujetos (en el mejor de los casos), son singulares y cada persona actúa de una manera que le es personal y que tiene una lógica sensible y argumentativa particular. Esencializar las emociones, ya sea por la vía naturalista o culturalista, de alguna forma implica cuestionar el carácter singular de los procesos históricos.

En esta línea de análisis, Barbara Rosenwein, que posiciona sus investigaciones desde el constructivismo, cuestiona las perspectivas de análisis que utilizan algunos referentes teóricos del campo de las emociones, como Norbert Elias y Michel Foucault. En su artículo "Worrying about emotions in History", publicado en 2002, Rosenwein señala que las conclusiones propuestas por estos autores, aun situándose desde una perspectiva culturalista, terminan por presentar una suerte de meta-narrativa histórica de las prácticas afectivas que tiende a sugerir un entendimiento teleológico de la historia. Llevando un poco más lejos la crítica que realiza Rosenwein, y sin pasar por alto las importantes contribuciones de dichos autores, las interpretaciones de Elias y Foucault, al mismo tiempo que ponen de manifiesto los impactos que la modernidad produjo en el desarrollo social, podrían reafirmar sus principios al elaborar teorías que tienden a entender que el control ha sido progresivo, incluso en los tiempos que anteceden a la modernidad. A mi entender, el cuestionamiento de Rosenwein, aunque acotado, apunta en la dirección correcta. Claramente, detener la mirada en las formas en que las emociones han sido controladas socialmente desde una perspectiva moderna nos permite delimitar algunos de sus impactos. Pero, a mi juicio, ese solo es el primer paso de una cadena analítica más extensa.

Dentro de la literatura historiográfica revisada, varios autores reseñan como antecedentes de la historia de las emociones los que han sido aquí descritos en términos generales. La mayoría de quienes hemos intentado abordar las emociones, lo hemos hecho construyendo categorías que consideramos atingentes a las posibilidades de nuestros casos de estudios y a las fuentes disponibles para ellos. En este sentido, podríamos considerar que los últimos veinte años, en los que la producción historiográfica sobre emociones ha hecho ebullición, han sido una especie de laboratorio disciplinar (Albornoz, 2016; Cordero et al., 2018; Gaune y Rolle, 2018). Unos pocos, como Reddy o Rosenwein, construyen teorías que tienen el objetivo de hacerlas abordables, racionales u objetivas para la historiografía. En el caso de Reddy (2001), crítico del constructivismo en su dimensión política, considerando aspectos de la psicología cognitiva y de la lingüística, sobre todo, propone el concepto de "regímenes emocionales". Ellos podrían analizarse desde los actos de habla que expresan emociones (emotives) y desde los grados de libertad emocional 
que permiten. Rosenwein (2002), por otro lado, introduce el concepto de "comunidades emocionales". Ellas aluden a contextos específicos en los cuales los individuos pueden hacer evaluaciones de comportamiento y expresión afectiva. La autora pone como ejemplos, la taberna, la iglesia o la escuela, entre otros, y en cada uno la afectividad estaría delimitada por un conjunto de normas sociales que pueden ser investigadas y definidas.

Pese a lo anterior, a juicio de Zaragoza:

"no se ha hecho un esfuerzo por definir de forma más o menos precisa qué son las emociones y, cuando así se ha intentado, los resultados no han sido plenamente satisfactorios, al anclar dicha definición en unas nociones de sujeto y de libertad occidentales. Lo que encontramos en la mayoría de los textos, por tanto, es una comprensión de las emociones más o menos "popular" (como la define el diccionario de la RAE: alteración del ánimo intensa y pasajera, agradable o penosa, acompañada de cierta conmoción somática), señalando, en algunos casos, su relación con los procesos de cognición sin que ello tenga ningún tipo de incidencia en la historia que se narra" (Zaragoza, 2013: 4).

Si bien, en términos generales, concuerdo con el cuestionamiento que realiza Zaragoza, estimo que el problema de estas aproximaciones radica en el anclaje que efectúan con las ciencias sociales e incluso con algunas ciencias más duras, especialmente, con la sociología, la psicología cognitiva, la neurociencia y la medicina en general. $\mathrm{O}$, en otros casos (y a consecuencia de un legítimo interés por encontrar mecanismos de objetivación), a una cierta tendencia a la generalización histórica, al resaltar el contexto social descuidando la singularidad histórica de la sensibilidad individual (o, en otras palabras, asumiendo que la cultura es más o menos determinante, sin cuestionar sus alcances). Sin duda, los hallazgos de estas disciplinas le permitieron a la historia justificar la historicidad de las emociones; sin embargo, considero que ese es solo el primer paso de una tarea mayor y que, creo, no descansa solo en ejercicios de objetivación de las emociones con el propósito de describir sus expresiones y contextos. Sin duda que reflexionar lo anterior es necesario y atingente, pero, a mi entender, la implicación de las emociones como temática historiográfica permite a la disciplina realizar ejercicios de elaboración de la experiencia histórica en un sentido más profundo. En este sentido, propongo revisar los fundamentos que se le han atribuido.

\section{El problema científico: ley y singularidad}

Hasta donde hemos visto, los autores reseñados suelen establecer los orígenes de la historia de las emociones en algunas investigaciones provenientes de las ciencias sociales e, incluso, de las ciencias de la vida. No es 
que ellos no ponderen los esfuerzos que la filosofía, la literatura o, incluso, la misma historia, han hecho por abordarlas, aun cuando éstos puedan haber sido tangenciales o parciales, sino que, según las perspectivas de análisis de los autores citados, las ciencias sociales habrían ofrecido fundamentos más sólidos con los que justificar su historicidad y, así, su tratamiento historiográfico. A partir de ahí se ha establecido una relación entre ciencias e historia de las emociones que es a lo menos problemática, en tanto que sus objetivos comprensivos y su entendimiento sobre el conocimiento podría apuntar en direcciones diferentes.

Esta es una discusión del siglo XX que, tal vez, algunos historiadores contemporáneos consideren zanjada. No obstante, en el campo de la historia de las emociones de las últimas décadas existen ciertos tratamientos historiográficos sobre las emociones que fundan sus interpretaciones en algunos de los hallazgos recientes de las ciencias. Estos ejercicios historiográficos parecen pretender sostener algunos de sus resultados en hallazgos de las ciencias de la vida. ${ }^{7}$ Más arriba notamos cómo Plamper (2014) advirtió a los historiadores sobre la complejidad de este asunto. En este sentido, es razonable considerar que la discusión respecto de la condición de la historia, si bien ha sido fuerte y frecuentemente discutida, no está resuelta.

Acerca de este asunto, en 1949 Marc Bloch señalaba que la historia sí debía considerarse una ciencia, no obstante, la noción de ciencia histórica de Bloch no es igual a la de ciencias de la naturaleza. En el prefacio de la Apología de la historia, el oficio del historiador (1993), Jacques Le Goff nos previene sobre el planteamiento de Bloch: "la historia es una ciencia, pero una ciencia entre cuyas características puede estar su flaqueza pero también su virtud, que consiste en ser poética porque no se la puede reducir a abstracciones, a leyes, a estructuras" (Bloch, 1993: 14). La poética a la que alude Le Goff se justifica en la nota de Bloch respecto a que los historiadores experimentan una "voluptuosidad de estudiar cosas singulares" (Bloch, 1993: 44). Más de veinte años después Paul Veyne (1984) cuestionó el carácter científico recién descrito al evaluar que las estrategias de investigación y escritura historiográfica no permitían considerar la existencia de un método de investigación disciplinar. En esta línea estaba de acuerdo con Bloch en que la historia no tenía la capacidad de configurar leyes. De todos modos, el autor no es un relativista, por el contrario, Veyne defiende la capacidad de la historia respecto de narrar acontecimientos verdaderos ya que se sostiene en documentos. En esta línea, el autor reafirma la noción de

Estos trabajos apuntan a otorgar cierta utilidad práctica al estudio historiográfico de las emociones, por ejemplo, en temáticas relacionadas a las políticas educativas. Antonio Damasio (2009), neurocientífico, ha servido de referencia conceptual para estos casos. Ver, también, Walton, S. (2005). 
singularidad disciplinar y escribe: "El individuo sólo cuenta históricamente por su especificidad, ya tenga un papel principal o el de un figurante entre millones" (Veyne, 1984: 47). De todos modos, la centralidad que tienen las nociones de "singularidad" y de "verdad" (entendida ésta como un conocimiento documentado y verídico) ha sido defendida desde Heródoto hasta nuestros días, aunque con matices y graduaciones diferentes a través del tiempo. La defensa de estas características parece relevante, tanto por sus fundamentos filosóficos (la historicidad del conocimiento histórico) como por cierta dimensión política y funcional para la comprensión de los asuntos del presente.

La noción de ciencia en la historia y, con ello, la noción de verdad como una que puede ser comprobada en los hechos fue particularmente discutida en la segunda mitad del siglo XX, posiblemente por efecto de ciertas corrientes filosóficas que permearon a las humanidades (Cárdenas, 2014). En la filosofía, primero, Ludwig Wittgenstein en 1921 elaboró una teoría respecto de la importancia del lenguaje en el desarrollo del conocimiento. Más tarde, en 1964, fue Gustav Bergmann quien tomó este problema y, finalmente, Richard Rorty popularizó el término "giro lingúistico" en 1968. Desde la teoría o filosofía de la historia, aunque cada uno desde perspectivas diferentes, Michel de Certeau, Jacques Derrida, Hans-Georg Gadamer, Michel Foucault, Paul Veyne y Hayden White, entre otros, tomaron ciertos postulados del giro lingüístico y de la filosofía del lenguaje para desarrollar sus investigaciones teóricas y cuestionar, en diferentes grados, el tipo de producción de conocimiento previo (Aurell, 2004).

Lo que de manera teórica se estaba poniendo en cuestión era el tipo de conocimiento que podía y debía producir la historia. Las preguntas que atravesaron estas investigaciones teóricas y filosóficas son varias (y, por supuesto, no pretendemos analizarlas en este trabajo), pero principalmente tienen que ver con el tipo de verdad que puede producir la historiografía; con la historicidad del conocimiento histórico; con el rol del historiador en las narraciones históricas; con el tipo de comprensión que permite y, por lo tanto, con sus alcances y, por último, con cómo escribirla. De hecho, en 1977, Hans-Georg Gadamer publicó una teoría hermenéutica del conocimiento histórico que puso el foco en el lenguaje y en la experiencia de la muerte y reclamó otro lugar para el conocimiento humanístico. Su intención se puede leer en la pregunta que desliza en el último ensayo de Verdad y Método II: "¿Cómo se convierte el lenguaje en arte?" (Gadamer, 2012: 402).

Lo que había detrás de estas cuestiones no fueron solo asuntos teóricos o solitarias consecuencias de razonamientos académicos o lógicos. Como muchas otras veces en la historia, el desarrollo intelectual estuvo vinculado a la contingencia y a los acontecimientos que marcaron el presente. 


\section{Presente, experiencia y emociones}

Para el mundo occidental, el siglo XX fue una época de cambios en varios sentidos. El desarrollo intelectual fue sistemáticamente permeado, primero, por las problemáticas sociales y económicas desencadenadas por la revolución industrial y la cuestión social, y después por la magnitud de la violencia en la Segunda Guerra Mundial y, sobre todo, por sus efectos. En este sentido, al menos hasta la década de 1980, en términos generales, predominaron enfoques de corte estructuralista como lo fueron la historia económica y social en Inglaterra o la escuela de los Annales en Francia, entre otras (Iggers, 2012). Sin embargo, entre los años 70 y 80 comenzaron a desarrollarse diferentes tipos de historia que apuntaban a descentralizar la manera en que había sido pensada y escrita. A veces estuvieron amparadas en el auge de la historia cultural y otras intentaron plantear corrientes independientes; en palabras de Peter Burke, se multiplicaron las "formas de hacer historia" (Burke, 1996). Entre ellas hay dos que me parecen fundamentales para pensar la historia de las emociones $\mathrm{y}$, también, para entenderlas como su fundamento más directo: la historia del tiempo presente y la historia de la experiencia.

Henry Rousso, en el libro La última catástrofe, plantea que "toda la historia contemporánea comienza con la "última catástrofe" " (Rousso, 2018: 12). Y, de hecho, en el caso europeo, la Segunda Guerra Mundial, pero también a nivel local, el golpe militar de 1973, marcan hasta hoy hitos en la historiografía, y no solo por la aparición de un nuevo tipo de historia que intenta hacerse cargo de las cuestiones del presente, si no porque, tal como lo sugiere Rousso, los acontecimientos excesivos, de alguna manera marcan el tono de ciertas interpretaciones y preocupaciones historiográficas.

Ciertamente, la historia del tiempo presente puso en entredicho el supuesto tradicional de la disciplina respecto de que la distancia histórica se hacía posible, en parte, gracias a la distancia temporal que tenía el historiador con los acontecimientos investigados (Traverso, 2016). El problema de cómo una memoria afectada puede trastocar la posibilidad de conocer la verdad ha sido una preocupación muy antigua. Tanto así que ya Aristóteles, en El arte poética (1948), hace una distinción entre la memoria y la rememoración. La primera sería la memoria afectada mientras la segunda estaría pasada por el cedazo del tiempo, por una cierta conciencia de la distancia temporal que permite ponderar el acontecimiento.

La radicalidad de la Segunda Guerra Mundial y la magnitud de sus consecuencias humanas impactaron también en las categorías académicas respecto de lo que hasta el momento se había considerado posible, verosímil. Con ello, las personas comenzaron a reclamar investigaciones sobre cómo habían ocurrido los hechos y, más tarde, interpretaciones sobre su pasado reciente en función de dimensiones judiciales y éticas que permitieran responder a 
la pregunta sobre la responsabilidad. Es en este contexto en el que historiadores como Jack Le Goff, Pierre Nora, Henry Rousso y Julio Arostegui, entre otros, se interesaron por sobre escribir temáticas del siglo XX posteriores a la Primera Guerra Mundial y, de esta forma, involucraron a la historiografía en los debates públicos. Así, estos intelectuales se imponían una importante tarea conceptual: modificar una comprensión según la cual una historia del tiempo presente no tenía legitimidad epistemológica para los conceptos historiográficos vigentes hasta ese momento.

Sin embargo, pareciera que el mandato tradicional de la historiografía cedió debido a la presión política y a la demanda social por explicaciones que otorgaran alguna coherencia a lo experimentado en Europa y no a las fortalezas teóricas que hicieron los defensores de la historia del tiempo presente. De hecho, en las primeras décadas de su desarrollo, los historiadores del tiempo presente no cuestionaron los fundamentos de la disciplina, sino más bien, sus disputas estuvieron en responder a las críticas que se le hicieron (Rousso, 2018). En este sentido, podría entenderse "como periodo histórico y no como forma de historizar" (Allier, 2018: 103), similar a otras grandes innovaciones temáticas introducidas en la historiografía del siglo XX.

Pese a que los aspectos teóricos no fueron resueltos, la preocupación por la distancia temporal respecto de los acontecimientos investigados, permitió que se instalara en la disciplina la pregunta por las implicancias teóricas que tenían aquellos eventos que, de alguna manera, excedían las capacidades de comprensión y que impactaban emocional y subjetivamente al historiador. Y, al mismo tiempo, pese a que los historiadores del tiempo presente no ahondaron en el problema de la verdad histórica, su ejercicio mismo la estaba cuestionando. Lo anterior posibilitó una nueva corriente, de menor importancia en términos de difusión académica, pero, a mi entender, de alcances superiores, que comenzó a interrogarse en cómo abordar aquellos acontecimientos cargados emotivamente que excedían al razonamiento lógico. Me refiero a la preocupación por la experiencia.

Y es que, como mencionamos antes, los trabajos de historia del tiempo presente, pretendieron dar cuenta, sobre todo, de hechos con los que se pudieran juzgar los acontecimientos, a veces también fueron usados como herramientas políticas, pero no intentaron analizar las experiencias excesivas y las emociones que ellas habían involucrado en la historia investigada.

En la década de 1980, sin embargo, se introdujo en la historia el concepto "experiencia" (Jay, 2009) de los sujetos y especialmente de las víctimas (Traverso, 2016; LaCapra, 2005). Desde las disciplinas humanistas y científico sociales, aunque de maneras diferentes, la pregunta por los acontecimientos ocurridos comenzó a ceder a otra que hasta nuestros días se sigue deshilvanando y trata acerca de la comprensión experiencial de los protagonistas y de 
la sociedad que los observó, pero también, resintió. Esta noción intelectual e histórica de la experiencia humana toca directamente el problema respecto de cómo estudiar históricamente las emociones y ha sido entendida como algo que, por su singularidad, difícilmente podría abordarse con las herramientas que proporcionan las disciplinas científicas que pretenden configurar leyes universales sobre el comportamiento humano (LaCapra, 2005).

Respecto de este tópico, Dominick LaCapra (2007) hace una distinción entre el acontecimiento y la experiencia. Mientras que el acontecimiento es el hecho puntual, la experiencia apunta a lo que los sujetos interpretaron, es decir, a un relato en movimiento que va del hecho a su interpretación y viceversa. Este autor plantea que hay acontecimientos excesivos que producen, del mismo modo, experiencias excesivas o traumáticas. Según la teoría psicoanalítica, corriente que LaCapra utiliza para elaborar su planteamiento, el trauma se define como aquello que no puede ser integrado coherentemente a la narrativa personal y/o social, y que "invade el presente y puede bloquear o anular posibilidades de futuro" (2007: 83), con lo cual la expectativa del conocimiento histórico resultaría, a su juicio, totalmente trastocada o imposibilitada, a menos de que planteemos nuevas estrategias de conocimiento. Es importante señalar que el trauma no deriva de cierto tipo de acontecimientos específicos sino de las herramientas con las que cuente un sujeto o una sociedad para integrar esas vivencias al discurso. Tomando como caso de estudio el Holocausto, el académico estadounidense sostiene que el impacto de este acontecimiento no solo generó efectos en quienes sobrevivieron, sino también en toda la sociedad que los observó y que ha resentido la capacidad de estudiar dicho acontecimiento en los estudios académicos e históricos. A la luz de los sucesos del siglo XX y de los efectos anteriormente señalados, este autor sugiere que las formas de trabajo que la disciplina utiliza, aun en la actualidad, están focalizadas en unas descripciones de los acontecimientos que, en sus pretensiones de objetividad, no permiten ahondar y comprender los cambios experienciales provocados.

El desarrollo teórico y práctico que han tenido los estudios sobre la memoria, la experiencia y los acontecimientos límites, específicamente en relación al holocausto (y en el caso latinoamericano, a las dictaduras), me parece de particular importancia para el estudio de las emociones porque, al mismo tiempo que cuestiona la distancia histórica, esboza interrogantes respecto de las fuentes primarias elaboradas a partir de aquellos acontecimientos excesivos. En otras palabras, el exceso no solo afecta a las personas sino también al tipo de material documental que producen los contemporáneos a los eventos sociales o personales que los hubieran excedido.

Si es que una emoción es visible en el mundo social (o en los documentos) por su notoriedad y por la disrupción que ejerce en el ámbito de lo cotidiano, entonces podríamos estar hablando, en algún sentido, de una suerte de 
acontecimiento excesivo. En la misma línea, si la posibilidad de comprender un acontecimiento emocional depende de las posibilidades de integración narrativa de una manera que es, al mismo tiempo, particular para cada individuo y distinta para cada momento temporal, entonces sería valioso pensar las emociones como gradualidades de disrupción de la coherencia racional de lo cotidiano que no deberían ser analizadas desde reglas universales, sino desde el contexto histórico en que suceden y desde aquel en que se las está estudiando. A mi juicio, la relación entre el pasado y el presente se convierte aquí en un imperativo metodológico.

A partir de lo anterior, vale la pena interrogarse respecto del momento histórico en que la historia de las emociones está naciendo. Resulta sintomático que, al tiempo que los eventos trágicos del siglo pasado se alejaran, comenzaron a documentarse alzas significativas en las tasas de depresión y otras afecciones del ánimo en el mundo entero. La Organización Mundial de la Salud informa que actualmente alrededor de trescientos millones de personas en el mundo sufren depresión y que es la principal causa de discapacidad laboral (OMS, 2018). Podríamos presumir que en el pasado estas cuestiones también afectaron a las sociedades, pero que no fueron documentadas como se está haciendo en el presente por un problema tecnológico. Sin embargo, la documentación, publicidad y el desarrollo científico vinculado a estos datos (niveles de felicidad y depresión en los países, suicidios, asesinatos pasionales, etc.), podría sugerir que estos tópicos constituyen actualmente un motivo de dolor que excede, con mucha más notoriedad que antes, a la racionalidad imperante en occidente. A partir de ahí, pienso que el mayor desafío de la historia de las emociones es constituirse como una nueva forma de hacer historia y no solo como un cambio temático que, al final del día, pueda estar apoyando los resultandos científicos y no construyendo una comprensión histórica de las emociones y de sus expresiones sociales. Dicho de otro modo, a mi entender este acto de comprensión debería ir más allá de una descripción histórica que atienda a confirmar o a refutar soluciones científicas a problemas sociales del presente.

Estimo que en los estudios sobre la historia del tiempo presente y, específicamente, en su vertiente respecto de la experiencia, hay claves que podrían reconocer una historiografía de las emociones que nos permita no solo describirlas sino, más bien, elaborarlas en relación al presente. Para terminar, destaco cuatro ideas preliminares que podrían ser de utilidad para reflexionar en torno a esta corriente historiográfica y a cómo plantea desafíos específicos respecto de los conceptos de "verdad", "subjetividad", "autonomía" y "libertad", entre otros.

Antes que entender la historia como un ejercicio descriptivo, creo que hay que entenderla como una posibilidad de elaborar fracturas del pasado que de alguna manera nos interpelan en el presente. 
Son las emociones, principalmente, las que evocan movimientos profundos de sentido a lo largo del tiempo, las que dan cuenta de cambios históricos profundos; esto es, la relación de los sujetos con sus contextos, con sus horizontes de posibilidad.

En mi opinión, no todos los temas "emocionales" pueden ser trabajados con la misma profundidad o, al menos, no todos poseen los mismos alcances de sentido. Al modo de lo descrito por LaCapra, sería interesante que empecemos a pensar en cómo debemos trabajar los distintos tipos de emociones del pasado de acuerdo con sus características, intensidad e impacto social.

Eventualmente, pensar una historia de las emociones requiere, en parte, un ejercicio comparado con el presente. Con las prevenciones necesarias para no mezclar o confundir los periodos históricos con la actualidad. Un trabajo comparativo podría permitir una relación entre el historiador y sus sujetos u objetos de estudio que no sea meramente instrumental, sino un ejercicio de compromiso con el tiempo y con la humanidad.

\section{Referencias bibliográficas}

\section{a) Documentos}

Organización Mundial de la Salud. (2018). Depresión. En https://www.who. int/es/news-room/fact-sheets/detail/depression, revisado el 5-II-2019.

\section{b) Artículos de libros y revistas}

Albornoz, M. E. (2016). "La historia de las emociones. Comienzos, autores, tendencias. Breve balance e inventario bibliográfico", en M. E. Albornoz (Directora) Sentimientos y justicia. Coordenadas emotivas en la factura de experiencias judiciales. Chile, 1650-1990. Santiago: Acto Editores, pp. 249-280.

Allier, E. (2018). "Balance de la historia del tiempo presente. Creación y consolidación de un campo historiográfico", en Revista de Estudios Sociales, № 65, pp. 100-112. En https://doi.org/10.7440/res65.2018.09, revisado el 20-XII-2018.

Aurell, J. (2004). "Los efectos del giro lingüístico en la historiografía reciente", en Rilce. Revista de Filología Hispánica, Vol. 20, № 1, pp. 1-16. En https:// www.unav.edu/publicaciones/revistas/index.php/rilce/article/view/26710, revisado el 10-XII-2018.

Bericat, E. (2000). "La sociología de la emoción y la emoción en la sociología", en Paper, №62, pp. 145-176. En https://ddd.uab.cat/pub/papers/0210286 2n62/02102862n62p145.pdf, revisado el 25-XI-2018. 
Burke, P. (2005), "Is There a Cultural History of the Emotions?", en P. Gouk, Penelope y H. Hills, Representing Emotions: New Connections in the Histories of Art, Music and Medicine. Aldershot: Ashgate, pp. 35-48.

Cárdenas, N. (2014). "El debate sobre la historia científica y la ambivalencia de la modernidad", en Política y cultura, № 41, pp. 111-142. En http://www.scielo.org. $\mathrm{mx} /$ scielo.php?script=sci_arttext\&pid=S0188-77422014000100006\&lng =es\&tlng=es, revisado el 20-X-2018.

Ekman, P. (1971). "Constants across cultures in the face and emotion", en Journal of Personality and Social Psychology, Vol. 17, N² 2, pp. 124-129.

Febvre, L. (1941). "La sensibilité et I'historie: Comment reconstituer la vie affective d' autrefois?", en Annales d'histoire sociale, Vol. 3, № 1-2, pp. 5-20. En https:// doi.org/10.1017/S1243256300003522, revisado el 15-X-2018.

Giazú, E., y A. Lara (2014) "Emociones y Ciencias Sociales en el s. XX: la precuela del giro afectivo", en Athenea Digital, № 14, pp. 263-288. En http://dx.doi. org/10.5565/rev/athenead/v14n1.1094, revisado el 20-X-2018.

Le Breton, D. (2013). "Por una antropología de las emociones", en Revista Latinoamericana de Estudios sobre Cuerpos, Emociones y Sociedad, RELACES, Vol. 10, No 4, pp. 69-79.

Montesinos, R. y G. Martínez (2001). "Los usos sociológicos de Norbert Elias", en Estudios Sociológicos, Vol. XIX, № 57, pp. 823-842.

Moscoso, J. (2015). "La historia de las emociones, ¿de qué es historia?", en Vínculos de Historia, N 4, pp. 15-27.

Stearns, P. y Stearns, C. (1985). "Emociology: Clarifyng the History of Emotion and Emotional Standards", en The American Historical Review, Vol. 90, $\mathrm{N}^{\circ} 4$, octubre, pp. 813-836. En http://dx.doi.org/10.2307/1858841, revisado el 20-XI-2018.

Plamper, J. (2014). "Historia de las emociones: caminos y retos", en Cuadernos de Historia Contemporánea, Vol. 36, junio, pp. 17-29.

Rosenwein, B. (2002). "Worrying about emotions in History", en The American Historical Review, Vol. 107, № 3, pp. 821-845.

Surrallés, A. (1998). "Entre el pensar y el sentir. La antropología frente a las emociones", en Anthropologica, Vol. 16, № 16, pp. 291-304.

Traverso, E. (2016). "Memoria e historia del siglo XX", en M. G. Acuña, P. Flier, M. González, B. Groppo, E. Hevia, L. López, N. Nicholls, A. Oberti, C. Bacci, S. Skura, E. Traverso Archivos y memoria de la represión en América Latina (1973-1990). Santiago: LOM Ediciones/Fasic, pp. 17-29. 
Zaragoza, J. (2013). "Historia de las emociones: una corriente historiográfica en expansión", en Asclepio, Vol. 65, № 1. En http://dx.doi.org/10.3989/asclepio/2013.12, revisado el 20-X-2018.

\section{c) Libros}

Arendt, H. (1995). De la historia a la acción. Barcelona: Paidós.

Aristóteles (1948). El arte poética. Buenos Aires: Espasa Calpe.

Berríos, G. (2013). Historia de los síntomas de los trastornos mentales: la psicopatología descriptiva desde el siglo XIX. México: Fondo de Cultura Económica.

Bloch, M. (1993). Apología para la historia o el oficio de historiador. México: Fondo de Cultura Económica.

Burke, P. (1996). Formas de hacer Historia. Madrid: Alianza Universidad.

Darwin, Ch. (1984). La expresión de las emociones en el hombre y en los animales. Madrid: Alianza.

Cordero, M., P. Moscoso-Flores y A. Viu (2018). Rastros y gestos de las emociones. Desbordes disciplinarios. Santiago: Editorial Cuarto Propio, Universidad Adolfo Ibáñez.

Damasio, A. (2009). En busca de Spinoza Neurobiología de la emoción y los sentimientos. Barcelona: Crítica.

Delgauff, B. (1968). La Historia como Progreso. Buenos Aires: Ed. Cirilo.

Durkheim, E. (2011). El Suicidio. Madrid: Ediciones Akal.

Elias, N. (1993). El proceso de la Civilización. Investigaciones sociogenéticas y psicogenéticas. Buenos Aires: Fondo de Cultura Económica.

Gadamer, G. (2012). Verdad y Método I y II. Salamanca: Ediciones Sígueme.

Gaune, R. y C. Rolle (Editores). (2018). Homo dolens. Cartografías del dolor: sentidos, experiencias, registros. Santiago: Fondo de Cultura Económica.

Geertz, C. (1983). Descripción densa: hacia una teoría interpretativa de la cultural. La interpretación de las culturas. Barcelona: Gedisa.

Iggers, G. (2012). La historiografía del siglo XX. Desde la objetividad científica al desafío posmoderno. Santiago: Fondo de Cultura Económica.

Huertas, R. (2012). Historia cultural de la psiquiatría. Madrid: Los Libros de la Catarata.

Jay, M. (2009). Cantos de experiencia. Variaciones modernas sobre un tema Universal. Buenos Aires: Paidós. 
LaCapra, D. (2005). Escribir la historia, escribir el trauma. Buenos Aires: Nueva Visión.

LaCapra, D. (2007). Historia en tránsito: Experiencia, identidad, teoría crítica. Buenos Aires: Fondo de Cultura Económica.

Le Breton, D. (2009). Las pasiones ordinarias. Antropología de las emociones. Buenos Aires: Nueva Visión.

Plampler, J. (2015). The History of emotions: An Introduction. Oxford: Oxford University Press.

Rousso, H. (2018). La última catástrofe. La historia, el presente, lo contemporáneo. Santiago: Editorial Universitaria.

Veyne, P. (1984). Cómo se escribe la historia. Foucault revoluciona la historia. Madrid: Alianza Editorial.

Walton, S. (2005). Humanidad. Una historia de las emociones. Madrid: Taurus.

Weber, M. (2002). Economía y Sociedad. Esbozo de sociología comprensiva. España: Fondo de Cultura Económica.

Wittgenstein, L. (2009). Cuadernos Azul y Marrón. Madrid: TECNOS. 